\title{
Substituição do farelo de soja pelo farelo de linhaça em dietas para a piava (Leporinus obtusidens)
}

\section{Replacement of soybean meal by linseed meal in diets for piava (Leporinus obtusidens)}

\author{
Dirleise Pianesso ${ }^{1}$; Rafael Lazzari²*; Patrícia Inês Mombach ${ }^{1}$; \\ Taida Juliana Adorian'; Juliano Uczay ${ }^{3}$; João Radünz Neto ${ }^{4}$; Tatiana Emanuelli ${ }^{5}$
}

\section{Resumo}

O objetivo deste trabalho foi avaliar a substituição do farelo de soja pelo de linhaça no crescimento de juvenis de piava. O experimento foi realizado no laboratório de piscicultura da UFSM/CESNORS, no período de março a abril de 2011. Foram utilizados 360 peixes (peso inicial $=9,0 \pm 2,5 \mathrm{~g}$ ), sendo estes acondicionados em um sistema de recirculação de água composto por 15 tanques $(250 \mathrm{~L})$, com temperatura média da manhã $=20,3 \pm 1,62^{\circ} \mathrm{C}$ e da tarde $=21,4 \pm 1,42^{\circ} \mathrm{C}$, durante 30 dias. Foram testadas cinco dietas, com níveis volumétricos de substituição do farelo de soja $(0,25,50,75$ e 100\%). A utilização de farelo de linhaça como fonte proteica proporcionou aos peixes o mesmo desempenho. O peso, comprimento total, comprimento padrão, ganho em peso relativo, fator de condição e taxa de crescimento específico das piavas não foram influenciados pelos tratamentos $(\mathrm{P}>0,05)$. Da mesma forma, a glicose plasmática, deposição de proteína corporal e a enzima quimiotripsina não apresentaram diferenças. A deposição de lipídios corporais foi mais bem expressa pelo modelo cúbico de regressão polinomial $(\mathrm{P}<0,05)$. A inclusão do farelo de linhaça proporcionou aumento na quantidade da enzima tripsina $(P<0,05)$. Conclui-se que o farelo de linhaça pode ser utilizado como fonte protéica em dietas para piava.

Palavras-chave: Enzimas digestivas, fontes protéicas vegetais, nutrição, peixes nativos, suplemento proteico

\begin{abstract}
The aim of this study was evaluate the replacement of soybean meal by linseed meal on growth of piava juveniles. The experiment was carried on fish farming laboratory of UFSM/CESNORS, on March to April, 2011. They were used $360 \mathrm{fish}$, (initial weight $=9.0 \pm 2.5 \mathrm{~g}$ ), which placed in a water re-use system composed by 15 tanks $(250 \mathrm{~L})$, with mean temperature in the morning $=20.3 \pm 1.62^{\circ} \mathrm{C}$ and in the afternoon $=21.4 \pm 1.42^{\circ} \mathrm{C}$, during 30 days. It were testes five diets with volumetric levels of soybean meal replace $(0,25,50,75$ e $100 \%)$. The use of the linseed meal provided same performance to the fish. The weight, total length, standard length, relative weight gain, condition factor and specific growth rate of the piavas were not affected by treatments $(\mathrm{P}>0.05)$. Similarly, the plasmatic glucose, body protein deposition and chymotrypsin enzyme no showed differences. The body lipid deposition was best expressed by the cubic polynomial regression model $(\mathrm{P}<0.05)$. The inclusion of linseed meal increased the amount of the trypsin enzyme $(\mathrm{P}<0.05)$. It concludes that the linseed meal can be used as protein source in diets for piava.
\end{abstract}

Key words: Digestive enzymes, vegetal protein sources, nutrition, native fish, protein supplement

\footnotetext{
1 Discente(s) de graduação em Zootecnia, Centro de Educação Superior Norte, Universidade Federal de Santa Maria, CESNORS/ UFSM, Palmeira das Missões, RS. E-mail: dina.zoot@hotmail.com; patimombach@hotmail.com; tj.adorian@hotmail.com

2 Prof. Adjunto, Dept ${ }^{\circ}$ de Zootecnia e Ciências Biológicas, CESNORS/UFSM, Palmeira das Missões, RS. E-mail: rlazzari@ufsm.br Discente de Mestrado do Programa de Pós-Graduação em Zootecnia, CCR/UFSM, Santa Maria, RS. E-mail: uczay@ufsm.br Prof. Associado, Dept ${ }^{\circ}$ de Zootecnia, CCR/UFSM, Santa Maria, RS. E-mail: jradunzneto@yahoo.com.br

Prof. Adjunto, Dept ${ }^{\mathrm{o}}$ de Tecnologia e Ciência dos Alimentos, CCR/UFSM, Santa Maria, RS. E-mail: tatiemanuelli@gmail.com Autor para correspondência
} 


\section{Introdução}

A aquicultura é a atividade agropecuária em maior expansão mundial. Apresentou significativo crescimento nos últimos anos, passando de 278 mil toneladas em 2003 para 415 mil em 2009, o que equivale a $35 \%$ de incremento em menos de uma década (MPA, 2011). Para o aumento da produção de pescado, são necessárias pesquisas que levem em conta as diferentes regiões brasileiras (CAMARGO; POUEY, 2005).

A produção de peixes nativos é uma das tendências da piscicultura, pois essas espécies evoluíram neste ambiente, que as tornam mais aptas ao cultivo (FRACALOSSI; ZANIBONI FILHO; MEURER, 2002). Além disso, apresentam índices zootécnicos satisfatórios, características organolépticas desejáveis de carne e boa aceitação pelo mercado consumidor (FRACALOSSI, et al., 2004).

A piava (Leporinus obtusidens) é encontrada nas bacias hidrográficas dos Rios Uruguai e Lago Guaíba, no Rio Grande do Sul. Possui hábito alimentar onívoro, ou seja, aproveita eficientemente as fontes proteicas de origem vegetal sendo esta uma característica favorável já que reduz o custo das dietas (FRACALOSSI; ZANIBONI FILHO; MEURER, 2002; RADÜNZ NETO et al., 2006). É bastante explorado na pesca esportiva e extrativista, o que tem levado a uma redução do estoque pesqueiro nos rios, podendo chegar em cultivo, entre 6 a 8 meses, a mais de $1 \mathrm{~kg}$ de peso. É procurada pelo sabor de sua carne e além dessa grande aceitação pelo consumidor, estudos mostram que no ambiente natural essa espécie pode chegar aos 5,2 Kg (ZANIBONI-FILHO et.al., 2004). As informações encontradas sobre a piava evidenciam a falta de estudos sobre a biologia e principalmente a criação desta espécie (MELLO et al., 1999; FILIPETTO et al., 2005).

Há perspectiva de grande aumento na oferta de farelos de origem vegetal no Brasil pelo incentivo que tem ocorrido à produção de biocombustíveis. $\mathrm{Na}$ produção de biocombustíveis os processos de extração de óleo geram grande quantidade de subprodutos (farelos), que podem ser utilizados na alimentação animal (SILVA; FREITAS, 2008). Estes subprodutos, em geral com alto valor proteico, custo baixo e homogeneidade quanto à composição permitem uma maior flexibilidade na formulação das dietas para peixes.

Entretanto por apresentarem fatores antinutricionais, afetam a eficiência de utilização dos nutrientes, prejudicando o crescimento dos peixes principalmente quando utilizadas como único ingrediente proteico da dieta (MEURER et al., 2005). Por outro lado, a combinação equilibrada de ingredientes proteicos favorece o sucesso nesta substituição, além de reduzir o impacto ambiental por excreção de nitrogênio e fósforo (JAHAN et al., 2003).

O farelo de soja é a fonte proteica vegetal mais utilizada em dietas para peixes pela sua grande disponibilidade, perfil de aminoácidos mais favorável e também mais palatável para a maioria dos peixes (COLDEBELLA; RADÜNZ NETO, 2002). Devido ao aumento do custo da soja nos últimos anos e pelo surgimento de outros resíduos vegetais no mercado, torna-se fundamental o conhecimento do efeito do uso destas fontes na alimentação dos peixes.

A linhaça é uma oleaginosa com grande potencial para produção de biocombustíveis, sendo adaptada ao cultivo no sul do Brasil (SOARES et al., 2009). O farelo de linhaça constitui uma boa fonte protéica de origem vegetal, possuindo 36\% de proteína bruta em média, porém apresenta deficiência nos aminoácidos essenciais lisina e metionina. Como fatores antinutricionais apresenta tanino, ácido fítico e polissacarídeos não amiláceos. Sua utilização em dietas para peixes depende diretamente do processamento utilizado para sua obtenção (MUKHOPADHYAY; RAY, 2001).

O objetivo deste trabalho foi avaliar a substituição do farelo de soja pelo farelo de linhaça no crescimento de juvenis de piava. 


\section{Material e Métodos}

O experimento foi conduzido durante 30 dias (março a abril de 2011), nas instalações do Laboratório de Piscicultura do Centro de Educação Superior do Norte do RS (UFSM-CESNORS), no município de Palmeira das Missões, RS (altitude de $639 \mathrm{~m}$, longitude oeste $53^{\circ} 18$ ' 49', latitude sul). Utilizou-se um sistema de recirculação de água, composto por 15 tanques de polipropileno revestidos com fibra de vidro (250L), com entrada e saída de água individuais. O sistema foi composto por um reservatório de água (2000L) para abastecimento dos tanques e biofiltro (pedra britada) para filtragem biológica. A água de abastecimento foi proveniente de poço artesiano. Foram utilizados 360 juvenis de piava (peso inicial $=9,0 \pm 2,5 \mathrm{~g}$ ), totalizando 24 peixes por tanque com 5 tratamentos e 3 repetições. Os juvenis, de ambos os sexos, foram oriundos de piscicultura localizada no município de Ajuricaba-RS.

O controle da qualidade da água foi realizado através de limpezas periódicas dos encanamentos que compõe o sistema de criação, sifonagem diária de resíduos dos tanques e do biofiltro, sendo posteriormente realizada renovação parcial da água do sistema e monitoramento dos parâmetros físicos e químicos da água. Diariamente foi mensurada a temperatura $\left({ }^{\circ} \mathrm{C}\right)$ da manhã e da tarde. A cada dois dias, foram mensurados amônia total (ppm), nitrito (ppm), oxigênio dissolvido (ppm) e $\mathrm{pH}$. Semanalmente, avaliou-se a alcalinidade (mg $\left.\mathrm{CaCO}_{3} \mathrm{~L}^{-1}\right)$ e a dureza $\left(\mathrm{mg} \mathrm{CaCO} \mathrm{L}^{-1}\right)$. Para aferição da temperatura utilizou-se termômetro (bulbo de mercúrio) e para as demais análises, foi utilizado kit colorimétrico-volumétrico (marca: Alfakit ${ }^{\circledR}$ ). A análise de amônia foi baseada no método Indotest, e a alcalinidade por neutralização (volumétrico), ambos descritos no manual da APHA (2005). O nitrito foi analisado pelo método proposto por Fries (1971) (método da alfa-naftilamina), e o pH pelo uso de indicador (AWWA, 1970).

Foram testados quatro níveis de substituição do farelode soja pelo farelo de linhaça $(25 ; 50 ; 75 ; 100 \%)$ incluídos na dieta e um tratamento controle (TC), sem inclusão de farelo de linhaça. A formulação das dietas experimentais foi baseada em Radünz Neto et al. (2006), que indica como formulação base: farelo de soja $(39,00 \%)$, glúten de trigo $(3,25 \%)$, milho triturado $(27,00 \%)$, farelo de arroz desengordurado $(22,75 \%)$, óleo de soja (3,00\%), sal comum $(1,00 \%)$, fosfato bicálcico (1,00\%), vitaminas e minerais $(3,00 \%)$, possuindo em sua composição $32 \%$ de proteína bruta. A composição bromatológica das rações experimentais esta descrita na tabela 1 .

Para fabricação das dietas experimentais os ingredientes foram pesados e posteriormente misturados, através de amassadeira industrial, até completa homogeneização. Então se adicionou água na mistura para realizar a peletização, e após a ração foi levada à estufa com circulação de ar forçado (24h) a uma temperatura de $55^{\circ} \mathrm{C}$. Depois da secagem, as rações foram moídas e peneiradas para a obtenção de grânulos de acordo com o tamanho dos peixes e armazenadas.

A alimentação dos peixes foi realizada duas vezes ao dia (9h:00, 16h30min), sendo fornecido $5 \%$ do peso vivo em ração, diariamente. Semanalmente os peixes de cada unidade experimental foram pesados para aferição da biomassa e ajuste no consumo de ração.

Foram realizadas duas biometrias para coleta de dados, no início e ao final do experimento (30 dias). Os dados coletados foram: peso ( $\mathrm{g}$ ) utilizando balança digital com duas casas decimais, comprimento total $(\mathrm{cm})$ e comprimento padrão (cm) através de ictiômetro graduado. A partir destas medidas biométricas e dos resultados das análises das dietas foram estimados: peso médio $(\mathrm{g})$; sobrevivência $(\%)$; comprimento total $(\mathrm{cm})$; comprimento padrão $(\mathrm{cm})$; taxa de crescimento específico $(\% /$ dia $)$ : TCE $=(\ln ($ peso final $)-\ln ($ peso inicial))/dias)*100; ganho em peso diário $(\mathrm{g})$ : GPR $=(($ peso final - peso inicial $) /$ peso inicial $) * 100$; fator de condição $(\mathrm{FC}=[($ Peso $\mathrm{x} 100) /($ Comprimento total $\left.\left.^{3}\right)\right]$ ). 
Tabela 1. Composição das dietas experimentais (g/kg.).

\begin{tabular}{|c|c|c|c|c|c|}
\hline \multirow{2}{*}{ Ingredientes } & \multicolumn{5}{|c|}{ Percentual de substituição de farelo de soja (\%) } \\
\hline & 0 & 25 & 50 & 75 & 100 \\
\hline Farelo de soja & 420 & 315 & 210 & 105 & 0 \\
\hline Farelo de linhaça & 0 & 105 & 210 & 315 & 420 \\
\hline Glúten de trigo & 110 & 120 & 150 & 170 & 200 \\
\hline Milho moído & 160 & 150 & 150 & 130 & 110 \\
\hline Farelo de arroz desengordurado & 250 & 250 & 220 & 220 & 210 \\
\hline Óleo de soja & 30 & 30 & 30 & 30 & 30 \\
\hline Vitaminas $^{1}$ e minerais ${ }^{2}$ & 10 & 10 & 10 & 10 & 10 \\
\hline Fosfato bicálcico & 10 & 10 & 10 & 10 & 10 \\
\hline \multirow[t]{2}{*}{ Sal } & 10 & 10 & 10 & 10 & 10 \\
\hline & \multicolumn{5}{|c|}{ Composição } \\
\hline Umidade & 113,3 & 117,3 & 129,1 & 132,4 & 131,2 \\
\hline Proteína & 336,2 & 305,7 & 310,6 & 316,1 & 312,7 \\
\hline Lipídios & 60,1 & 67 & 68,2 & 78,1 & 81,4 \\
\hline Cinzas & 79,3 & 78,1 & 71,2 & 73,2 & 70,2 \\
\hline Lisina & 19,2 & 18,1 & 17,7 & 17,0 & 16,7 \\
\hline Metionina & 5,3 & 5,5 & 5,8 & 6,1 & 6,5 \\
\hline Metionina + Cistina & 9,2 & 9,2 & 9,4 & 9,5 & 9,8 \\
\hline Treonina & 11,2 & 10,8 & 10,6 & 10,3 & 10,1 \\
\hline Triptofano & 4,4 & 4,4 & 4,5 & 4,6 & 4,7 \\
\hline Valina & 16,3 & 16,2 & 16,7 & 16,9 & 17,4 \\
\hline Isoleucina & 14,8 & 14,5 & 14,9 & 15,0 & 15,4 \\
\hline Leucina & 26,0 & 25,0 & 25,0 & 24,6 & 24,7 \\
\hline Fenilalanina & 17,2 & 16,8 & 17,1 & 17,1 & 17,5 \\
\hline Histidina & 8,6 & 8,3 & 8,2 & 8,0 & 8,0 \\
\hline Arginina & 21,6 & 21,6 & 22,0 & 22,3 & 22,9 \\
\hline
\end{tabular}

${ }^{1}$ Composição da mistura vitamínica (kg de produto/MigPlus): Ác. Fólico: 1200mg, Ác. Nicotínico: 24000mg, Ác. Pantotênico: 12000mg, Biotina: 48 mg, Vit.A: $1200000 U I$, Vit. B1: 4800mg, Vit. B2: 4800mg, Vit. B6: 4800mg, Vit. B12: 4800mcg, Vit. C: 48 g, Vit. D3: 200000UI, Vit. E: $12000 \mathrm{mg}$, Vit. K3: 2400mg.

${ }^{2}$ Composição da mistura mineral (kg de produto/MigPlus): Cobalto: 10mg, Cobre: 3000mg, Ferro: 50000mg, Iodo: 100mg, Manganês: 20000mg, Selênio: $100 \mathrm{mg}$, Zinco: $3000 \mathrm{mg}$.

${ }^{3}$ Valores de umidade, proteína, lipídios e cinzas foram analisados e valores de aminoácidos foram estimados pelo NRC (2011) e pela tabela Rostagno (2011).

Fonte: Elaboração dos autores.

Ao final do experimento foram feitas coletas de sangue em quatro animais por tratamento, por punção na veia caudal. Imediatamente após a coleta realizou-se a leitura da glicose com aparelho medidor portátil (Accu-check Active ${ }^{\circledR}$ ). Aos 30 dias dez peixes por tratamento, foram capturados e abatidos para análise de composição centesimal das carcaças. Os intestinos de quinze peixes (três por tratamento) foram coletados para análise enzimática, os quais foram posteriormente homogeneizados com solução tampão $\mathrm{pH}$ 7,0 e centrifugados. O sobrenadante obtido foi utilizado para análise de tripsina e quimiotripsina, conforme metodologia descrita por Hummel (1959).

Em todos os procedimentos, os peixes passaram por jejum (12 horas), foram previamente submetidos à sedação utilizando o anestésico eugenol diluído em água (concentração de $0,02 \%$ ) e foram abatidos por hipotermia. Foram realizadas análises de composição corporal dos peixes, onde se determinou os valores para cinzas, umidade, gordura e proteína bruta. 
A umidade foi determinada pela perda de peso após $4 \mathrm{~h}$ a $60^{\circ} \mathrm{C}$ em estufa com circulação forçada de ar, seguida de $8 \mathrm{~h}$ a $105^{\circ} \mathrm{C}$. O conteúdo de cinzas foi determinado a $550^{\circ} \mathrm{C}$ (método 923.03) de acordo com AOAC (1995). A proteína bruta ( $\mathrm{N}$ x 6,25) foi determinada pelo método de micro Kjeldahl (método 960.52) da AOAC (1995). Os lipídios foram quantificados seguindo o método de Bligh e Dyer (1959).

O delineamento experimental foi o inteiramente casualizado, com cinco tratamentos e três repetições (15 tanques). Os dados obtidos foram submetidos ao teste de normalidade (Shapiro-Wilk) e detecção de observações anormais ("outliers"), onde foram excluídas as maiores ou menores que a média ( $2 *$ desvio padrão). Aplicou-se análise de regressão aos dados. As médias de tripsina foram ajustadas ao peso inicial e comparadas pelo teste de PDIFF. Para realização das análises, foi utilizado o software Statistical Analysis System (SAS, 2000).

\section{Resultados e Discussão}

Os valores de qualidade da água verificados no experimento foram: temperatura da manhã $(20,3$ $\left.\pm 1,62^{\circ} \mathrm{C}\right)$ e da tarde $\left(21,4 \pm 1,42^{\circ} \mathrm{C}\right)$, oxigênio dissolvido $\left(3,66 \pm 0,21 \mathrm{mg} \mathrm{L}^{-1}\right), \mathrm{pH}(7,1 \pm 0,41)$, alcalinidade $\left(38,8 \pm 4,38 \mathrm{mg} \mathrm{CaCO} 3 \mathrm{~L}^{-1}\right)$, dureza $\left(53,2 \pm 10,6 \mathrm{mg} \mathrm{CaCO} 3 \mathrm{~L}^{-1}\right)$, amônia $(0,66 \pm 0,48$ $\left.\mathrm{mg} \mathrm{L}^{-1}\right)$ e nitrito $\left(0,02 \pm 0,009 \mathrm{mg} \mathrm{L}^{-1}\right)$ Embora a média dos níveis de oxigênio tenham sido abaixo do recomendado (menos de $5 \mathrm{mg} \mathrm{L}^{-1}$ ), não foi observado mortalidade ou sintomas de anóxia nos peixes.

Não houve efeito no peso médio $(\mathrm{P}>0,05)$ dos peixes alimentados com dieta contendo farelo de soja (TC) e farelo de linhaça $(25,50,75$ e 100\%) durante os trinta dias experimentais (Tabela 2). Juvenis de piava alimentados com dieta contendo farelo de soja apresentaram maior peso (16 g) aos 60 dias, quando comparado aos peixes que receberam dietas contendo levedura de cana e farinha de carne e ossos, evidenciando a capacidade desta espécie em aproveitar alimentos de origem vegetal (RADÜNZ NETO et al., 2006). Para tilápias a substituição da farinha de peixe pela mistura de farelos de soja, algodão, girassol e linhaça em diferentes níveis $(0$, $25,50,75$ e 100\%) não interferiu no desempenho (EL-SAIDY; GABER, 2003).

Tabela 2. Parâmetros zootécnicos ${ }^{(1)}$ de juvenis de piava (Leporinus obtusidens).

\begin{tabular}{|c|c|c|c|c|c|}
\hline \multicolumn{6}{|c|}{ NÍVEIS DE SUBSTITUIÇÃO DO FARELO DE SOJA $(\%)^{(2)}$} \\
\hline Variáveis ${ }^{(3)}$ & $0 \%$ & $25 \%$ & $50 \%$ & $75 \%$ & $100 \%$ \\
\hline PI (g) & $9,13 \pm 0,89$ & $8,63 \pm 1,30$ & $8,46 \pm 0,49$ & $9,43 \pm 0,81$ & $8,84 \pm 0,33$ \\
\hline $\mathrm{PM}(\mathrm{g})$ & $16,36 \pm 2,97$ & $14,88 \pm 0,90$ & $15,54 \pm 2,32$ & $17,58 \pm 1,84$ & $15,90 \pm 1,82$ \\
\hline $\mathrm{CT}(\mathrm{cm})$ & $11,24 \pm 0,55$ & $10,86 \pm 0,18$ & $10,99 \pm 0,39$ & $11,30 \pm 0,50$ & $11,17 \pm 0,27$ \\
\hline $\mathrm{CP}(\mathrm{cm})$ & $9,10 \pm 0,46$ & $8,76 \pm 0,13$ & $8,86 \pm 0,38$ & $9,18 \pm 0,36$ & $9,03 \pm 0,24$ \\
\hline GPR (\%) & $78,38 \pm 20,61$ & $86,64 \pm 13,64$ & $83,19 \pm 17,53$ & $86,35 \pm 4,58$ & $80,33 \pm 26,50$ \\
\hline FC & $1,14 \pm 0,05$ & $1,16 \pm 0,01$ & $1,16 \pm 0,06$ & $1,17 \pm 0,02$ & $1,14 \pm 0,06$ \\
\hline TCE $(\% /$ dia $)$ & $1,91 \pm 0,38$ & $2,07 \pm 0,24$ & $2,01 \pm 0,31$ & $2,07 \pm 0,08$ & $1,94 \pm 0,48$ \\
\hline
\end{tabular}

${ }^{(1)}$ PI: Peso inicial; PM: Peso médio final; CT: Comprimento total; CP: Comprimento padrão; GPR: Ganho em peso relativo; FC: Fator de condição; TCE: Taxa de crescimento específico; ${ }^{(2)}$ Tratamentos; ${ }^{(3)}$ Valores apresentados como média \pm desvio padrão; Não ocorreu efeito significativo $(\mathrm{P}>0,05)$ em nenhuma das variáveis acima.

Fonte: Elaboração dos autores. 
Não houve efeito $(\mathrm{P}>0,05)$ dos tratamentos sobre comprimento total e comprimento padrão. Em estudos realizados com pós-larvas de piava a substituição do glúten de trigo por $75 \%$ de farelo de soja proporcionou o melhor comprimento total e padrão em relação ao tratamento sem inclusão de farelo de soja, sem comprometer o desenvolvimento inicial durante vinte e um dias experimentais (FILIPETTO et al., 2005). A média dos valores de comprimento total $(11 \mathrm{~cm})$ e o comprimento padrão $(9 \mathrm{~cm})$ obtidos neste estudo são bastante parecidos aos valores encontrados em trabalho com juvenis de piava, onde os peixes alimentados com a dieta contendo farelo de soja apresentaram maior comprimento total $(11,1 \mathrm{~cm})$ do que os peixes alimentados com as dietas levedura de cana $(10,7 \mathrm{~cm})$ e farinha de carne e ossos $(10,7 \mathrm{~cm})$. Os animais que receberam a dieta farelo de soja apresentaram comprimento padrão superiores $(9,2 \mathrm{~cm})$ aos juvenis de piava alimentados com a dieta farinha de carne e ossos (8,7cm) (RADÜNZ NETO et al., 2006).

Os valores de fator de condição não foram influenciados $(\mathrm{P}>0,05)$ pelo tratamento contendo farelo de soja e os tratamentos com níveis crescentes de farelo de linhaça. Este resultado indica que a proporção entre o peso e o comprimento total dos peixes manteve-se constante, não sendo afetados pelas dietas experimentais. Em média os peixes apresentaram fator de condição em torno de 1,1 semelhantes aos valores obtidos por Radünz Neto et al. (2006) com fator de condição de 1,1 com 40 dias de criação e com a mesma espécie. Para $L$. macrocephalus, o fator de condição é modificado pela dieta apresentando efeito quadrático, com nível máximo de inclusão de $17,43 \%$ de farelo de algodão (SOUZA et al., 2004).

Não houve efeito $(\mathrm{P}>0,05)$ das dietas sobre a taxa de crescimento específico. Juvenis de piava alimentados com dietas contendo farelo de soja apresentaram maior taxa de crescimento específico quando comparados com peixes alimentados com levedura de cana e farinha de carne e ossos (RADÜNZ NETO et al., 2006).
Para a carpa comum a taxa de eficiência proteica não apresentou diferença entre as dietas que tinham farinha de penas, farinha de carne ou concentrado proteico de soja com inclusão de $6 \%$ na composição das dietas (JAHAN et al., 2003).

Neste estudo, não houve efeito $(\mathrm{P}>0,05)$ da substituição do farelo de soja pelo farelo de linhaça no ganho em peso relativo de juvenis de piavas, durante os 30 dias experimentais. $\mathrm{O}$ ganho em peso relativo de carpa-húngara apresentou efeito linear negativo da substituição de farinha de carne suína pela mistura de farelos vegetais (BERGAMIN et al., 2010).

Em estudos com rohu (Labeo rohita) constatouse que o farelo de linhaça dependendo do método empregado pode substituir, até $50 \%$ da proteína da farinha de peixe (MUKHOPADHYAY; RAY, 2001). O farelo de linhaça pode ser incluído em até 25\% do total de proteína da dieta, sem comprometer o desempenho de larvas de carpa comum. A dieta controle (farinha de peixe como fonte protéica) e as dietas com farelo de linhaça (25 e 50\% da proteína da dieta) e amendoim ( $25 \%$ da proteína da dieta) apresentaram maior aceitabilidade em relação às dietas com maiores níveis de inclusão de farelos vegetais para esta espécie de carpa (HASAN; MACINTOSH; JAUNCEY, 1997).

Os resultados dos parâmetros de desempenho desse trabalho com a piava mostram que apesar das controversas sobre a utilização e aproveitamento do farelo de linhaça por diferentes espécies de peixes, a piava consegue aproveitar de forma eficiente esta fonte de origem vegetal. Constata-se que na dieta contendo $42 \%$ de farelo de linhaça, temos uma contribuição deste ingrediente em $43 \%$ do total da proteína desta dieta.

Os resultados obtidos neste estudo podem estar relacionados com as estruturas especializadas encontradas no intestino da piava, os cecos pilóricos, que possuem características histológicas e histoquímica semelhantes às do intestino adjacente (ROTTA, 2003) sugerindo que sirvam 
para aumentar a superfície de contato intestinal proporcionando um maior aproveitamento dos alimentos. Estes resultados também podem estar associados a características especificas dos peixes do gênero Leporinus como o hábito alimentar onívoro (ANDRIAN et al., 1994) e à boa digestibilidade dos ingredientes de origem vegetal (GONÇALVES; FURUYA, 2004).
A deposição de proteína corporal (Tabela 3) não foi afetada $(\mathrm{P}>0,05)$ pelos tratamentos. Para carpashúngaras alimentadas com ditas com substituição gradual $(0,25,50,75$ e100\%) da proteína da farinha de carne suína pela mistura dos farelos de soja e canola não foram encontradas diferenças para a deposição de proteína corporal (BERGAMIN et al., 2010).

Tabela 3. Parâmetros bioquímicos de juvenis de piava (Leporinus obtusidens).

\begin{tabular}{lcccccc}
\hline \multicolumn{7}{c}{ NÍVEIS DE SUBSTITUIÇÃO DO FARELO DE SOJA (\%) } \\
\hline Variáveis ${ }^{(2)}$ & $0 \%$ & $25 \%$ & $50 \%$ & $75 \%$ & $100 \%$ & P \\
GLIC & $52,67 \pm 5,51$ & $50 \pm 8,66$ & $57,33 \pm 6,81$ & $57,33 \pm 2,87$ & $55,67 \pm 6,66$ & NS \\
DPC & $1,28 \pm 0,39$ & $1,33 \pm 0,04$ & $1,35 \pm 0,34$ & $1,39 \pm 0,17$ & $1,26 \pm 0,39$ & NS \\
DLC & $1,02 \pm 0,21$ & $0,88 \pm 0,06$ & $0,96 \pm 0,14$ & $1,39 \pm 0,14$ & $1,22 \pm 0,18$ & $\mathrm{Cúbica}^{(3)}$ \\
QUIM & $3879,55 \pm 202,3$ & $4565,77 \pm 791,5$ & $4478,91 \pm 419,8$ & $4686,06 \pm 432,6$ & $4818,14 \pm 586,8$ & NS \\
\hline
\end{tabular}

(1) Tratamentos; ${ }^{(2)}$ Médias seguidas por \pm desvio padrão; ${ }^{(3)} \mathrm{y}=1,03-0,02 \mathrm{X}+0,0007 \mathrm{X}^{2}-0,000004 \mathrm{X}^{3}, \mathrm{r}^{2}=0,60, \mathrm{P}=0,02 ; \mathrm{NS}$ : Não significativo $(\mathrm{P}>0,05)$; GLIC: Glicose $\left(\mathrm{g} \mathrm{dL}^{-1}\right)$; DPC: Deposição de proteína corporal $(\mathrm{g})$; DLC: Deposição de lipídio corporal (g); QUIM: quimotripsina (U/mg de proteína).

Fonte: Elaboração dos autores.

Houve efeito $(\mathrm{P}<0,05)$ da substituição do farelo de soja pelo farelo de linhaça na deposição de lipídio corporal das piavas. Ocorreu efeito cúbico para esta variável, sendo o maior valor observado no tratamento $75 \%$ de substituição do farelo de soja pelo farelo de linhaça. Para a piava, poucas são as informações que remetem a valores normais de deposição lipídica. Juvenis de Dicentrarchus labrax apresentaram aumento da gordura corporal quando alimentados com dietas contendo maior nível de ingredientes vegetais (KAUSHIK et al., 2004).

Não houve efeito $(\mathrm{P}>0,05)$ dos tratamentos sobre a glicose plasmática. A determinação da glicose plasmática é importante para o conhecimento do metabolismo dos peixes em função das alterações da dieta, além de servir como indicativo de saúde (KUMAR et al., 2010) estando relacionada à condições de estresse. Dietas contendo apenas fontes vegetais proporcionam maiores níveis de glicose plasmática por conta da maior quantidade de carboidratos presentes nesses ingredientes (KUMAR et al., 2010). Isso explica porque não houve diferença nos níveis de glicose nesse experimento, pois todos os tratamentos tiveram como ingredientes subprodutos oriundos de grãos e oleaginosas.

A atividade de quimiotripsina não sofreu efeito dos crescentes níveis de inclusão do farelo de linhaça $(\mathrm{P}>0,05)$. Este resultado ressalta a eficiência que a piava apresenta na digestão e aproveitamento dos ingredientes vegetais, o que já foi constatado em estudos com juvenis (RADÜNZ NETO et al., 2006). Em estudo com carpas capim (Ctenopharyngodon idella) os peixes alimentados somente com ração tiveram a menor atividade de quimiotripsina na porção anterior e posterior do trato em comparação com as carpas alimentadas com capim teosinto (COSTA et al., 2011). As carpas possuem alto potencial de secreção de proteases (HIDALGO; UREA; SANZ, 1999), principalmente para digerir as proteínas dos ingredientes de origem vegetal, que possuem menor digestibilidade (KUZ'MINA, 1990). 
Observou-se maior atividade de tripsina nos peixes alimentados com diferentes níveis de farelo de linhaça na dieta. $\mathrm{O}$ tratamento contendo apenas farelo de soja $(0 \%)$ apresentou menor atividade de tripsina (Figura 1) sendo igual ao tratamento com
$50 \%$ de substituição do farelo de soja pelo farelo de linhaça. O tratamento $25 \%$ de substituição do farelo de soja pelo farelo de linhaça proporcionou maior atividade de tripsina para juvenis de piava não diferindo dos tratamentos 75 e 100\% de substituição.

Figura 1. Atividade de tripsina de piavas alimentadas com dietas contendo níveis de farelo de linhaça em substituição ao farelo de soja. Médias ajustadas com letras diferentes, na coluna, apresentam diferença significativa pelo teste de Pdiff $(\mathrm{P}<0,05)$.

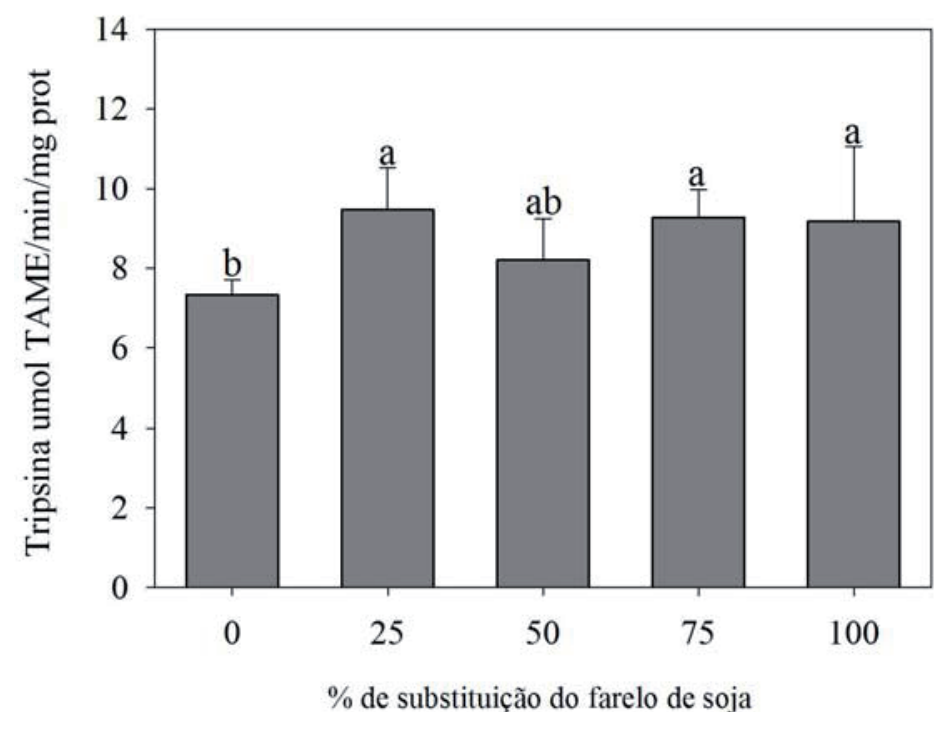

Fonte: Elaboração dos autores.

Em trabalhos realizados com jundiá, a atividade de tripsina e quimiotripsina foi menor em peixes alimentados com dietas contendo farelo de soja e levedura de cana, e dietas com farelo de soja (LAZZARI et al., 2010). A atividade de tripsina em carpas capim (Ctenopharyngodon idella) foi maior nos peixes alimentados exclusivamente com capim, sendo que as carpas que receberam somente ração tiveram a menor atividade desta enzima (COSTA et al., 2011).

Este resultado pode estar relacionado com os fatores antinutricionais existentes no farelo de soja, mais especificamente os inibidores de tripsina que impedem a completa utilização de suas proteínas pelo organismo dos monogástricos, paralisando a ação da tripsina, responsável pela digestão das proteínas. A composição da dieta e o hábito alimentar de cada espécie influencia a atividade das enzimas digestivas dos peixes (RAY, 1988). Associado a isso, as dietas contendo mais linhaça continham mais glúten de trigo, o que pode ter contribuído para a variação da atividade enzimática.

Para a carpa capim, existe correlação entre a quantidade de alimento e a secreção de enzimas digestivas (DAS; TRIPATHI, 1991). O aumento da atividade de tripsina em peixes alimentados com dietas com alto teor de fibra pode evidenciar uma forma de compensar a baixa qualidade e quantidade de proteína na dieta consumida. Outra hipótese, é que os maiores valores de tripsina nos tratamentos com farelo de linhaça podem estar relacionados com a maior inclusão de glúten de trigo na formulação 
da dieta (tabela 1) e este por ser um ingrediente com um maior grau de processamento é também mais digestível, o que acaba aumentando os níveis da enzima em questão.

Em trabalhos realizados com o jundiá (Rhamdia quelen) e com o pintado (Pseudoplatystoma corruscans) verificou-se que a atividade das proteases alcalinas (tripsina e quimotripsina) pode sofrer maior influência do tipo de dieta do que pela variação da quantidade de proteína (LUNDSTEDT; MELO; MORAES, 2004; MELO et al., 2006). Em relação à atividade de proteases alcalinas os peixes onívoros como o pacu (Piaractus mesopotamicus) estão mais sujeitos aos fatores inibitórios da dieta do que peixes carnívoros (PÉREZ et al., 2003).

As informações sobre a utilização de ingredientes em dietas para piava ainda são bastante limitadas. Estudos envolvendo a utilização de diferentes fontes proteicas bem como a influência da proporção destes ingredientes sobre o aproveitamento dos nutrientes e a composição corporal são de grande importância para a espécie. Neste aspecto é fundamental que se estude o efeito da utilização das fontes vegetais nas dietas para piava, proporcionando maior segurança e flexibilidade nas formulações das dietas. Ressaltase que a substituição do farelo de soja pelo farelo de linhaça, dependerá das oscilações nos valores de comercialização e disponibilidade destes no mercado.

\section{Conclusão}

O farelo de linhaça pode ser utilizado como substituto do farelo de soja em dietas para juvenis de piava (Leporinus obtusidens).

\section{Agradecimentos}

Ao $\mathrm{CNPq}$, pela bolsa de iniciação científica (PIBIC-UFSM 2011) concedida as acadêmicas Dirleise Pianesso e Taida Juliana Adorian; à Ingal - Indústria Gaúcha de Alimentos Ltda pelo fornecimento do farelo de arroz desengordurado; à Tangara Foods pelo fornecimento do glúten de trigo; à Cotrimaio - Cooperativa Agro-pecuária Alto Uruguai Ltda. pelo fornecimento do farelo de soja e milho; ao Pólo de Modernização TecnológicaPMTec da Universidade Regional Integrada de Frederico Westphalen - RS, por disponibilizar suas instalações para a fabricação das dietas experimentais.

\section{Aprovação no Comitê de Ética}

Este trabalho foi aprovado na comissão de ética no uso de animais (CEUA/UFSM) sob parecer número 059/2011, considerando seus aspectos éticos e metodológicos.

\section{Referências}

ANDRIAN, I. F.; COSTA DÖRIA, C. R.; TORRENTE, G.; FERRETTI, C. M. L. Espectro alimentare similaridade na composição de dieta de quatro espécies de Leporinus Characiformes, Anastomidae), do Rio Paraná (2210'$\left.22^{\circ} 50^{\prime} \mathrm{S} / 53^{\circ} 10^{\prime}-53^{\circ} 40^{\prime} \mathrm{W}\right)$, Brasil. Revista Unnimar, Marília, v. 16, p. 97-106, 1994.

ASSOCIATION OF OFFICIAL ANALYTICAL CHEMISTS - AOAC. Official methods of analysis. 16. ed. Arlington: AOAC International, 1995.

AMERICAN PUBLIC HEALTH ASSOCIATION APHA. Standard methods for the examination of water and waste water. $21^{\text {th }}$ ed. Washington: DC, 2005. $1368 \mathrm{p}$.

AMERICAN WATER WORKS ASSOCIATION AWWA. Processos simplificados para exame e análise da água. São Paulo: AWWA, 1970. 276 p.

BERGAMIN, G. T.; RADÜNZ NETO, J.; EMANUELLI, T.; LAZZARI, R.; MASCHIO, D.; KNAPP, V. Substituição da farinha de carne suína por fontes vegetais em dietas para carpa-hungara. Pesquisa Agropecuária Brasileira, Brasília, v. 45, n. 10, p. 1189-1197, 2010.

BLIGH, E. G.; DYER, W. J. A rapid method of total lipid extraction and purification. Canadian Journal of Biochemistry and Physiology, Ottawa, v. 37, p. 911-917, 1959.

CAMARGO, S. G. O.; POUEY, J. L. O. F. Aquicultura - um mercado em expansão. Revista Brasileira Agrociência, Pelotas, v. 11, n. 4, p. 393-396, 2005. 
COLDEBELLA, I. J.; RADÜNZ NETO, J. Farelo de soja na alimentação de alevinos de jundiá (Rhamdia quelen). Ciência Rural, Santa Maria, v. 32, n. 3, p. 499-503, 2002.

COSTA, M. L.; RADÜNZ NETO, J.; LAZZARI, R.; VEIVERBERG, C. A.; SUTILI, F. J.; LORO, V. L. Enzimas digestivas de juvenis de carpa capim alimentados com forragem e ração. Archivos de Zootecnia, Córdoba, v. 60 , n. 231, p. 563-570, 2011.

DAS, K. M.; TRIPATHI, S. D. Studies of digestive enzymes of grass carp (Ctenopharyngodon idella Val.). Aquaculture, Amsterdam, v. 92, p. 21-32, 1991.

EL-SAYDI, D. M. S. D.; GABER, M. M. A. Replacement of fish meal with a mixture of different plant protein sources in juvenile Nile tilapia, Oreochromis niloticus (L.) diets. Aquaculture Research, Oxford, v. 34, n. 13, p. 1119-1127, 2003.

FILIPETTO, J. E. S.; RADÜNZ NETO, J.; SILVA, J. H. S.; LAZZARI, R.; PEDRON, F. A.; VEIVERBERG, C. A. Substituição de fígado bovino por glúten de milho, glúten de trigo e farelo de soja em rações para pós-larvas de piava (Leporinus obtusidens). Ciência Rural, Santa Maria, v. 35, n. 1, p. 192-197, 2005.

FRACALOSSI, D. M.; MEYER G.; SANTAMARIA, F. M.; WEINGARTNER, M. ZANIBONI-FILHO, E. Desempenho do jundiá, Rhamdia quelen, e do dourado, Salminus brasiliensis, em viveiros de terra na região sul do Brasil. Acta Scientiarum, Animal Sciences, Maringá, v. 26, n. 3, p. 345-352, 2004.

FRACALOSSI, D. M.; ZANIBONI FILHO, E.; MEURER, S. No rastro das espécies nativas. Panorama da Aqüicultura, Rio de Janeiro, v. 12, n. 2, p. 43-49, 2002.

FRIES, J. Análisis de trazas: métodos fotométricos comprobados. Darmstadt: Merck, 1971. 184 p.

GONÇALVES, G. S.; FURUYA, W. M. Digestibilidade aparente de alimentos pelo piavuçú, Leporinus macrocephalus. Acta Scientiarum, Maringá, v. 26, n. 2, p. 165-169, 2004.

HASAN, M. R.; MACINTOSH, D. J.; JAUNCEY, K. Evaluation of some plant ingredients as dietary protein sources for common carp (Cyprinus carpio L.) fry. Aquaculture, Amsterdam, v. 151, n. 1-4, p. 55-70, 1997.

HIDALGO, M. C.; UREA, E.; SANZ, A. Comparative study of digestive enzymes in fish with different nutritional habits. Proteolytic and amylase activities. Aquaculture, Amsterdam, v. 170, n. 3-4, p. 267-283, 1999.

HUMMEL, B. C. W. A modified spectrophotometric determination of chymotrypsin, trypsin and thrombin. Canadian Journal of Biochemistry and Physiology, Ottawa, v. 37, n. 12, p. 1393-1399, 1959.
JAHAN, P.; WATANABE, T.; KIRON, V.; SATOH, $\mathrm{S}$. Balancing protein ingredients in carp feeds to limit discharge of phosphorus and nitrogen into water bodies. Fisheries Science, Oxford, v. 69, n. 2, p. 226-233, 2003.

KAUSHIK, S. J.; COVÈS, D.; DUTTO, G.; BLANC, D. Almost total replacement of fish meal by plant protein sources in the diet of a marine teleost, the European seabass, Dicentrarchus labrax. Aquaculture, Amsterdam, v. 230, n. 1-4, p. 391-404, 2004.

KUMAR, V.; HARINDER, P. S.; MAKKAR, A.; AMSELGRUBER, W.; BECKER, K. Physiological, haematological and histopathological responses in common carp (Cyprinus carpio L.) fingerlings fed with differently detoxified Jatropha curcas kernel meal. Food and Chemical Toxicology, Oxford, v. 48, n. 8-9, p. 20632072, 2010.

KUZ MINA, V. Temperature influence on the total level of proteolytic activity in the digestive tract of some species of freshwater fishes. Journal Ichthyology, Moscou, v. 30, n. 2, p. 97-109, 1990.

LAZZARI, R.; RADÜNZ NETO, J.; PEDRON, F. A.; LORO, V. L.; PRETTO, A.; GIODA, C. R. Protein sources and digestive enzyme activities in jundiá (Rhamdia quelen). Scientia Agrícola, Piracicaba, v. 67, n. 3, p. 259-266, 2010.

LUNDSTEDT, L. M.; MELO, J. F. B.; MORAES, G. Digestive enzymes and metabolic profile of Pseudoplatystoma corruscans (Teleostei, Siluriformes) in response to diet composition. Comparative Biochemistry and Physiology. Part B. Biochemistry \& Molecular Biology, Amsterdan, v. 137, n. 3, p. 331-339, 2004.

MELLO, R. F.; MOURA, M. A. M.; VIEIRA, I.; CYRINO, J. E. P. Suplementação da dieta de alevinos de piauçú (Leporinus obtusidens) com vitamina C. Scientia Agrícola, Piracicaba, v. 56, n. 4, p. 1223-1231, 1999.

MELO, J. F. B.; LUNDSTEDT, L. M.; METÓN, I.; BAANANTE, I. V.; MORAES, G. Effects of dietary levels of protein on nitrogenous metabolism of Rhamdia quelen. Comparative Biochemistry and Physiology Part A. Molecular \& Integrative Physiology, Amsterdam, v. 145, n. 2, p. 181-187, 2006.

MEURER, F.; HAYASHI, C.; BOSCOLO, W. R.; SCHAMBER, C. R.; BOMBARDELLI, R. A. Fontes protéicas suplementadas com aminoácidos e minerais para a tilápia do Nilo durante a reversão sexual. Revista Brasileira de Zootecnia, Viçosa, v. 34, n. 1, p. 1-6, 2005.

MINISTÉRIO DA PESCA E AQUICULTURA - MPA. Aquicultura/produção - participação da aquicultura no setor pesqueiro nacional. 2011. Disponível em: <http:// www.mpa.gov.br/aquicultura/informacoes/producao>. Acesso em: 05 out. 2011. 
MUKHOPADHYAY, N.; RAY, A. K. Effects of amino acid supplementation on the nutritive quality of fermented linseed meal protein in the diets for rohu, Labeo rohita, fingerlings. Journal of Applied Ichthyology, Oxford, v. 17, n. 5, p. 220-226, 2001.

NATIONAL RESEARCH COUNCIL - NRC. Nutrient requerements of fish and shrimp. Washington: The National Academic Press, 2011. 376 p.

PÉREZ, J. J.; WICKI, G. A.; MOYANO, F. J.; ALARCÓN, F. J. Evaluación del efecto de inibidores de proteasa presentes em ingredientes vegetales utilizables en piensos para dos espécies piscícolas cultivadas em Argentina: pacu (Piaractus mesopotamicus) y pejerrey (Odontesthes bonariensis). In: CONGRESSO IBEROAMERICANO VIRTUAL DE ACUICULTURA, 2., 2003, España. Anais... España: Editora Univ. Zaragoza, 2003. p. 442-454.

RADÜNZ NETO, J.; LAZZARI, R.; PEDRON, F. A.; VEIVERBERG, C. A.; BERGAMIN, G. T.; CORRÊIA, V.; FILIPETTO, J. E. S. Alimentação da piava (Leporinus obtusidens) com diferentes fontes proteicas. Ciência Rural, Santa Maria, v. 36, n. 5, p. 1611-1616, 2006.

RAY, A. K. On the digestive enzymes in three Indian freshwater perches in relation to food and feeding habits. Journal Inland Fishery Society India, Barrackeore, v. 20, n. 1, p. 1-5, 1988.

ROSTAGNO, S. Tabelas brasileiras para aves e suinos: composição de alimentos e exigências nutricionais. Viçosa: UFV, 2011. 252 p.
ROTTA, M. A. Aspectos gerais da fisiologia e estrutura do sistema digestivo dos peixes relacionados à piscicultura. Corumbá: Embrapa Pantanal, 2003. 49 p.

STATISTICAL ANALYSIS SYSTEM INSTITUTE SAS. User' guide. Versión 8.1, Cary, NC, 2000.

SILVA, P. R. F.; FREITAS, T. F. S. Biodiesel: o ônus e o bônus de produzir combustível. Ciência Rural, Santa Maria, v. 38, n. 3, p. 843-851, 2008.

SOARES, L. L.; PACHECO, J. T.; BRITO, C. M.; TROINA, A. A.; BOAVENTURA, G. T.; GUZMÁNSILVA, M. A. Avaliação dos efeitos da semente de linhaça quando utilizada como fonte de proteína nas fases de crescimento e manutenção em ratos. Revista de Nutrição, Campinas, v. 22, n. 4, p. 483-491, 2009.

SOUZA, S. R.; HAYASHI, C.; SOARES, T.; ANDRADE, L. S. Avaliação do efeito de diferentes níveis de farelo de algodão sobre o desempenho e a composição corporal de alevinos de piavuçú (Leporinus macrocephalus). Boletim do Instituto de Pesca, São Paulo, v. 30, n. 2, p. 127-134, 2004.

ZANIBONI-FILHO, E.; NUÑER, A. P. O. Fisiologia da reprodução e propagação artificial dos peixes. In: CYRINO, J. E. P. et al. (Ed.). Tópicos especiais em piscicultura de água doce tropical intensiva. São Paulo: TecArt, 2004. p. 45-73. 
